\title{
Quantifying dispersion in an estuary: A Lagrangian drifter approach
}

\author{
D. Spencer $\dagger$, C.J. Lemckert + , Y. Yut, J. Gustafson $\dagger$, S.Y. Lee $\dagger$, H. Zhang \\ $\dagger$ Australian Rivers Institute \\ Griffith University \\ \$ School of Engineering \\ Griffith University \\ Gold Coast, 4222, Australia \\ Gold Coast, 4222, Australia \\ d.spencer@griffith.edu.au \\ c.lemckert@griffith.edu.au
}

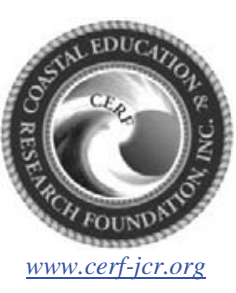

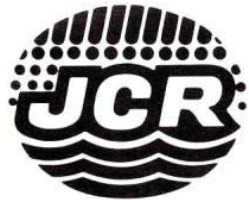

www.JCRonline.org

\section{ABSTRACT}

Spencer, D., Lemckert, C.J., Yu, Y., Gustafson, J., Lee, S.Y., Zhang, H., 2014. Quantifying Dispersion in an Estuary: A Lagrangian Drifter Approach. In: Green, A.N. and Cooper, J.A.G. (eds.), Proceedings $13^{\text {th }}$ International Coastal Symposium (Durban, South Africa), Journal of Coastal Research, Special Issue No. 70, pp. 029-034, ISSN 0749-0208.

Describing the physical drivers of water bodies plays an integral role in the marine environment. Lagrangian drifters are used to describe hydrodynamics, where tracking groups (clusters) of drifting floats is performed to determine the dispersion behaviour in the water. Using two types of Lagrangian drifters released in Moreton Bay, Australia, the dispersion behaviour is determined over the duration of a semi-diurnal spring tide cycle. A Self-Locating Datum Marker Buoy (SLDMB) was designed as the first drifter type. The second drifter (Small Drifter) was designed to be approximately half the size of the SLDMB. SLDMB and Small Drifter clusters were deployed for approximately 16hrs and 9-12hrs, respectively. Their trajectories and dispersion were influenced by the oscillating tidal current during the course of the drifter deployment, as well as fluctuating wind speed and direction. The Small Drifters exhibited a higher degree of dispersion than the SLDMBs; illustrating that the different drifter design had a significant impact on their susceptibility to wind induced shear dispersion - a consideration that all drogue based studies need to consider when interpreting results. A MIKE 3 model was used to assist with the investigation at hand using a dispersion coefficient of $0.2 \mathrm{~m}^{2} / \mathrm{s}$. The model required further adjustments with respect to tidal forcing and bathymetry resolution in order to enhance dispersion simulation.

ADDITIONAL INDEX WORDS: Lagrangian drifter, dispersion, SLDMB, estuary.

\section{INTRODUCTION}

Coastal regions host unique environments that range from softshores to rocky shores, hilly or flat coastal plains, narrow or wide coastal shelves and a wide variety of wetlands. Among the wide variety of wetlands are shallow water environments known as estuaries. Estuaries act as the transition zone between rivers, land, and coastal oceans; providing habitats for a large diversity of marine life. These environments are commonly subject to processes such as planktonic larval distribution, discharged contaminants, and potentially harmful suspended sediment plumes. Analysing surface water dispersion provides very useful information; as it drives not only the flow field but also a lot of biological, chemical, and sedimentological constituents (Manley, 2010).

The analysis of Lagrangian dispersion in coastal environments has been extensively performed through many studies in order to investigate the trajectories of such various constituents. It has been proven that Lagrangian trajectory analysis is a very valuable tool when predicting the fate and origin of specific water masses (Jönsson et al., 2011). The data provided by trajectory analysis can be used to compute Lagrangian dispersion, delivering insight into the flow dynamics which is unforeseen when analysing Eulerian data (Sabet \& Barani, 2011). In order to obtain such useful information from Lagrangian trajectories, methods have been implemented that practices the act of deploying surface tracers and

DOI: 10.2112/SI70-006.1 received 20 December 2013; accepted 21 February 2014. (c) Coastal Education \& Research Foundation 2014 tracking their trajectory path.

Surface tracers need to be deployed in a manner that allows them to be carried by the surface current all the while tracking their geographic location. In theory, it is possible to compute the trajectories of drifting objects, with known shape and buoyancy, given the net result of the balance of forces acting on them from wind, surface currents, and waves (Zhang and Chan, 2003; Breivik \& Allen, 2008). There are two main tracers commonly used in Lagrangian dispersion studies, surface drifters and fluorescent dye. Although tracking dye-patch growth is a valid method used for assessing water dispersion, solid floating objects are a lot easier to track both visually and with the aid of GPS units. With this in mind, the use of cleverly designed drifting floats deployed in the water has become a realistic option for measuring dispersion, commonly referred to as Lagrangian drifters.

Lagrangian drifters used in the water are floating instruments installed with different types of GPS devices, allowing the positions of the drifters to be retrieved after deployment or in real time. Since the early 1990's, evolutions of Lagrangian drifters have been made with the instrument float design and the equipment used to build them (Charria et al., 2012). For consideration during the design stage, drifters must be built with sufficient current following properties and therefore must be equipped with an effective drogue (Huhn et al., 2012). Tracking is performed using GPS satellite links for different types of drifters including Self-locating Datum Marker Buoys (SLDMB) (Marin \& Delgado, 2007); or even small drifters made with basic materials such as PVC (Sabet \& Barani, 2011). SLDMBs and small drifters 
collect geographic displacement data over a specified time interval. In theory, windage and inertial forces should have a negligible effect on the drifters over time; as only a small portion of the drifters (casing where GPS units are contained) are exposed above the water surface (Sabet \& Barani, 2011), and the portion of the drifter sitting above the water surface is highly aerodynamic. The data recorded from the drifters is then used to derive the dispersion behaviour of the water body. In order to calculate the dispersion characteristics of the drifters, the following equation can be used:

$$
K=\frac{1}{4} \frac{\partial\left(\sigma_{x} \sigma_{y}\right)}{\partial t}
$$

Where $K$ is defined as the dispersion coefficient computed using the longitudinal (x) and latitudinal (y) cluster displacement variance, $\sigma_{x} \sigma_{y}$, of the drifters with respect to time, $t$ (Tseng, 2002).

To assist with the dispersion study using Lagrangian drifters, a hydrodynamic model was used. Hydrodynamic models provide an administrative tool for decision making stakeholders to apply the right measures to restore endangered coastal environments (Zacharias \& Gianni, 2008). Valuable information is produced from not only accurate results but also from the visual illustrations generated by the model output. The model used to assist with this study was MIKE 3; a 3D hydrodynamic model designed by the DHI Group. MIKE 3 is a generalised mathematical modelling system and is regularly applied to studies such as coastal circulation; water pollution; and environmental impact assessments (DHI Water \& Environment, 2001). The system is based on the numerical solution of the 3D incompressible Reynolds-averaged Navier-Stokes (RANS) equations that are invoked with the hydrostatic pressure and Boussinesq assumptions. Many models are capable of reproducing state variables to within an order of magnitude, but most still need to be evaluated more intensively before their integrity can be verified (Lewis \& Allen, 2009). The assessment of a hydrodynamic model begins with measuring physical factors that affect the hydrodynamics in the region of interest. For the study at hand, two types of Lagrangian drifters were used to spot check the dispersion modelling capability of a MIKE 3 model.

\section{METHODS}

Quantifying dispersion in Moreton Bay estuary involved the use of two (2) types of Lagrangian drifters. A total of eight (8) drifters were deployed, four (4) for each type of drifter, at three (3) chosen locations with relatively unique spatial surroundings. The two types of drifters were deployed as two separate clusters from a research vessel during a semi-diurnal spring tide and their trajectory routes were tracked using GPS units. MIKE 3 was set up with a detailed domain map which included shoreline and bathymetric data as well as the wind and tide information. Results obtained from the drifters were to be spot checked against MIKE 3 to assess its capability when it comes to simulating dispersion.

\section{Study Site}

Moreton Bay estuary is situated in southeast Queensland, Australia, just beyond the coastline of Queensland's capital city,
Brisbane. Brisbane has been the fastest growing city in Australia, with the highest population density occurring along the Brisbane River and major industrial ports occurring near the mouth of the river (Narayan \& Pandolfi, 2010). This sub-tropical estuary is a large shallow embayment, ranging from depths of $<1-50 \mathrm{~m}$, flanked by four large sand islands and contains several small islands (Chilvers et al., 2005).

\section{Drifter Design}

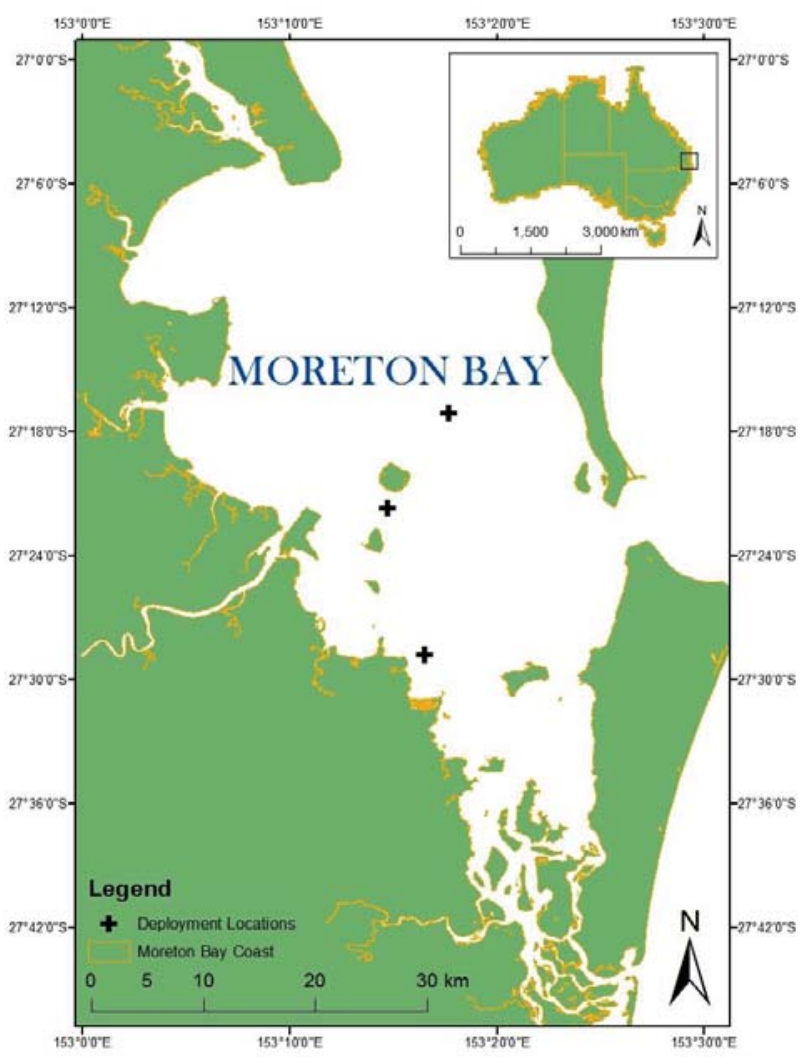

Figure 1. Map of Moreton Bay illustrating the three chosen locations for the drifters to be deployed.

Two different Lagrangian surface drifters were designed, constructed and used in this study: the SLDMB and Small Drifter. There were four (4) SLDMB drifters in total and these were large Self-Locating Datum Marker Buoys (SLDMB) built using strong aluminium materials for the frame (Figure 2a). The SLDMB was designed following a similar approach used by Poulain (1999), who designed drifters based on the Coastal Dynamics Experiment (CODE) study conducted in the early 1980's. A total of eight arms held four drag-producing vanes in place which acted together as a drogue for stability and control. A PVC container bolted to the top of the frame was used as water proof storage for the GPS unit. The GPS unit used for the SLDMB was the SPOT 2 Satellite GPS Messenger unit (Figure 2b) activated with the "Track Progress" feature, allowing the positions of the SLDMBs to be tracked in near real-time using Google Maps with a position fixing error of 


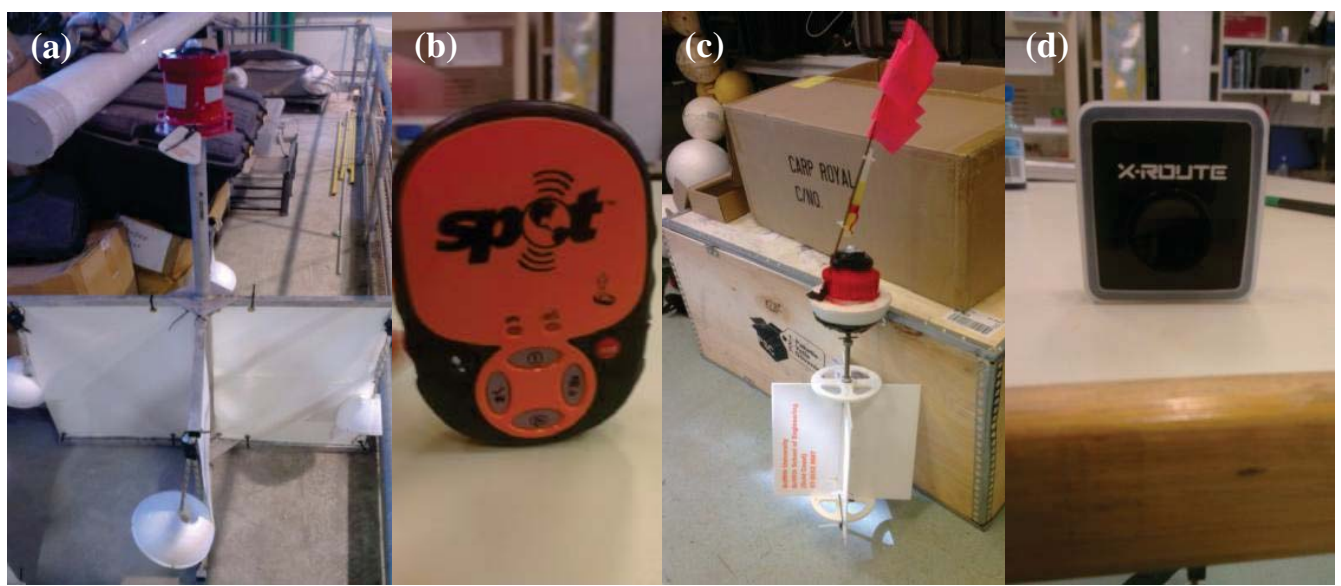

Figure 2. Self-Locating Datum Marker Buoy (a) tracked in near real-time using the Spot 2 Satellite Messenger (b). The Small Drifter (c) was tracked using the X-Route GPS (d) data logger.

$\sim 5 \mathrm{~m}$. For the Small Drifters, four (4) drifters were constructed and designed based on the SLDMB; however, the drifter was greatly reduced in size and more cost-effective materials were used (Figure 2c). For the GPS container, a small PVC union was capped at one end using high density plastic material and a pipe end cap sealed the other end. A threaded piece of rod was used to act as the spine of the drifter, allowing the rod to be screwed into the high density plastic end of the union. Two circular discs were used to hold in place four vanes at the top and bottom. The discs and vanes were laser cut and made entirely out of Perspex white acrylic. This smaller drifter was tracked using a simpler X-Route GPS data logger (Figure 2d), which logged the drifter's position throughout the duration of the deployment. Once each deployment was finished and the Small Drifters were retrieved the X-Route Manager software mapped their trajectory path using Google Maps with a position fixing error of $\sim 25 \mathrm{~m}$.

\section{MIKE 3}

The MIKE 3 domain map of Moreton Bay was generated using coastline data provided by the National Oceanic and Atmospheric Administration (NOAA) and bathymetry by Maritime Safety Queensland (Yu et al., 2013 a, 2013b). Predicted tidal heights provided by the DHI global tide model were used at the open boundaries in the domain (Figure 3). Wind conditions were accounted for using 1 minute datasets from the inner reciprocal marker wind station supplied by the Australian Bureau of Meteorology (BOM). Initial sea temperature and salinity data was described using satellite remote sensing observations provided by NASA and the Queensland Ecosystem Health Monitoring Program (EHMP). The "spin-up" period (time required for model to reach stable status) allocated for the model was one month and the trajectory started from rest with surface elevation and velocity set to zero. The dispersion was simulated using the MIKE 3 HD (Hydrodynamic) and PT (Particle Tracking) modules with a constant dispersion coefficient value of $0.2 \mathrm{~m}^{2} / \mathrm{s}$.

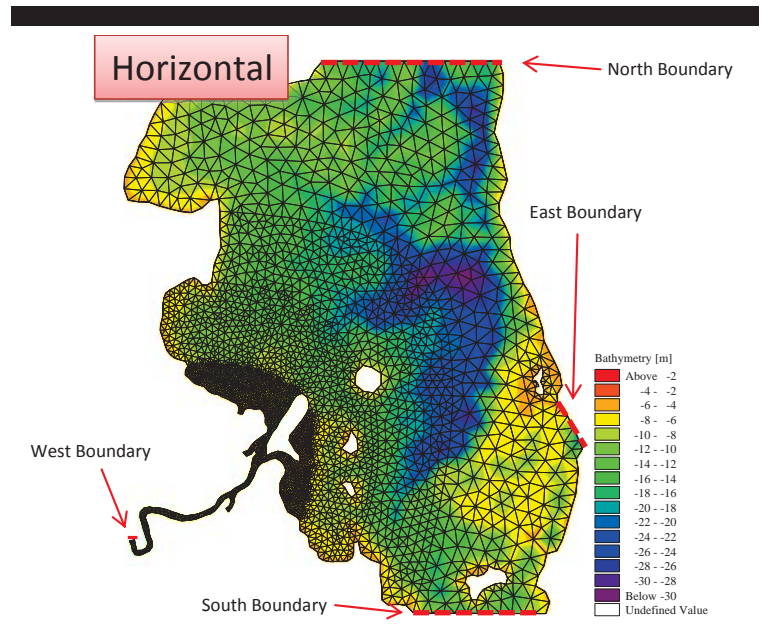

Figure 3. MIKE 3 horizontal spatial domain of Moreton Bay

\section{RESULTS}

Field data obtained was used to quantify the dispersion behaviour of the two types of drifters. The physical drivers of their dispersion in Moreton Bay were evident. The tidal forcing had a significant effect on the fate of all the drifter trajectories as well as the dispersion behaviour. Evidence is illustrated using ArcMAP and a convex hull approach was implemented to exhibit both drifter types dispersion behaviour (Figure 4). Data was graphically presented using MATLAB for both the SLDMBs and Small Drifters. The dispersion coefficient $(K)$ was computed using linear regression of the displacement variance $\left(\sigma_{x} \sigma_{y}\right)$ shift after each recorded time step $-10 \mathrm{~min}$ for the SLDMBs and 30min for the Small Drifters. 
The trajectories of all the drifters from both the SLDMB cluster and Small Drifter cluster followed a very similar route as they all headed south-west in an anti-clockwise direction. The SLDMBs experienced very little dispersion until they were approaching peak high tide, where the drifters started to spread out; however, the largest amount of dispersion started to occur during the ebb tide. The Small Drifters experienced more dispersion than the SLDMBs before peak high tide and they also experienced more dispersion during the ebb tide.

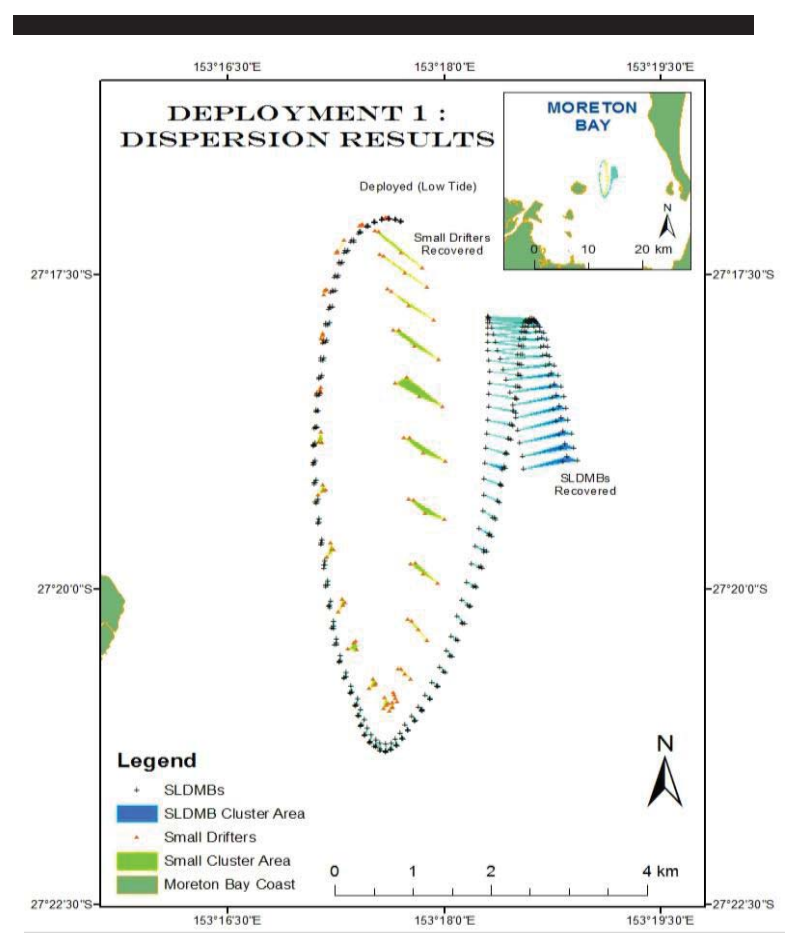

Figure 4. Trajectory paths and dispersion behaviour of the SLDMBs and Small Drifters at the first deployment location.

\begin{tabular}{|l|l|}
\hline Small Drifter deployment & $12 \mathrm{hrs}$ \\
\hline SLDMB deployment & $16 \mathrm{hrs}$ \\
\hline Tidal elevation & $0.2-2.5 \mathrm{~m}$ \\
\hline Wind & $4-8 \mathrm{~m} / \mathrm{s}$ \\
\hline Surface current & $0-0.5 \mathrm{~m} / \mathrm{s}$ \\
\hline
\end{tabular}

Table 1. Deployment duration for each drifter type and physical driving conditions during deployment

The dispersion graphs reflect the behaviour illustrated in Figure 4 , as the dispersion coefficient describes the dispersion "events" observed as the tide was approaching peak high and low (Figure 5a). A smaller spike is also observed just before the largest spreading starts to occur around the $9^{\text {th }}$ hour. The gradual spreading is consistent with the maximum drifter distance and displacement variance, exhibiting a linear growth trend at the $9^{\text {th }}$ hour before plateauing at $\sim 14^{\text {th }}$ hour (Figure $5 \mathrm{~b}$ ). On average, the Small Drifters revealed a greater value for the dispersion coefficient as well as a greater degree of fluctuation in comparison with the SLDMBs (Figure 5c). The dispersion coefficient shows a gradual increasing trend with the first peak related to the much quicker initial spread of the drifters before 2 hours. The second
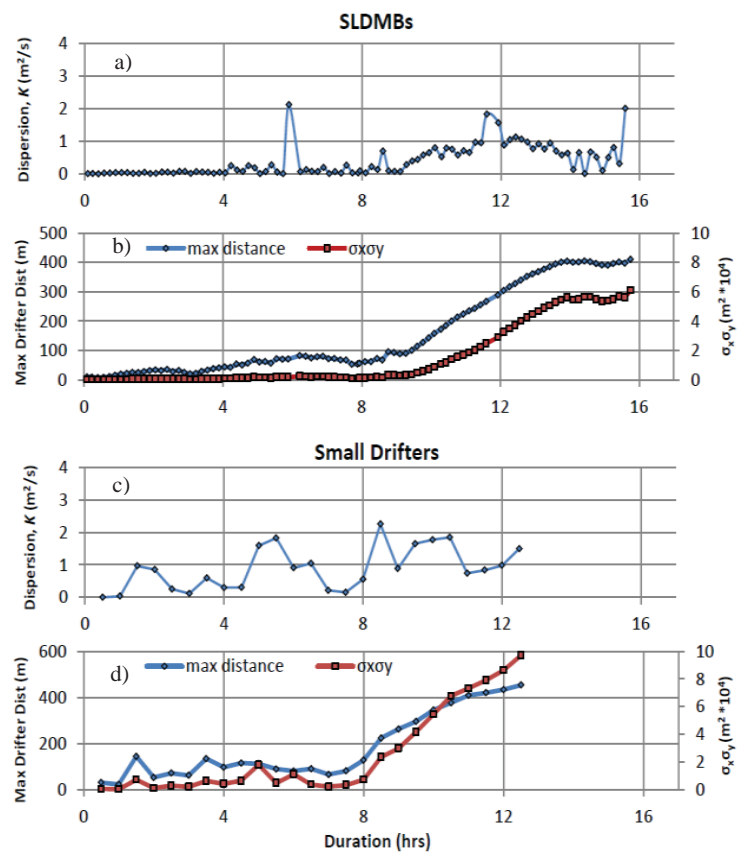

Figure 5. Dispersion and displacement variance of the SLDMBs and Small Drifters throughout the duration of the deployment

(larger) peak appears to be related to the drifters approaching high tide, and the greatest peak occurs just before the greatest spreading starts. The greatest spreading of the Small Drifters happened around the $8^{\text {th }}$ hour (Figure $5 d$ ); $~ 1$ hour earlier than the SLDMBs. Overall dispersion was greater than what was seen by the SLDMBs.

\section{SLDMBs vs. Small Drifters}

Additional graphs were generated to help gain a better understanding of any relationships between the two different drifters. The drifters were different from one another with respect to their size, weight, materials, and GPS units used; however, both were designed based on the style used by Poulain (1999). Considering the SLDMBs and Small Drifters experienced very different dispersion behaviour, and consequently different values for their displacement variance and dispersion coefficient; they have been plotted together on the same graph in an attempt to identify similarities.

Figure 6 illustrates the dispersion and displacement variance for both the SLDMBs and Small Drifters over the deployment duration at the first location. The displacement variance of both drifters (Figure 6a) shows an obvious trend that they both share as the drifters spread out over time; however, the Small Drifters start spreading earlier. The Small Drifters clearly encounter a larger amount of dispersion and at a faster rate (Figure 6b). The dispersion coefficient for the Small Drifters is consistently higher than the SLDMBs until the last 1.5 hours where both clusters are closely correlating. 


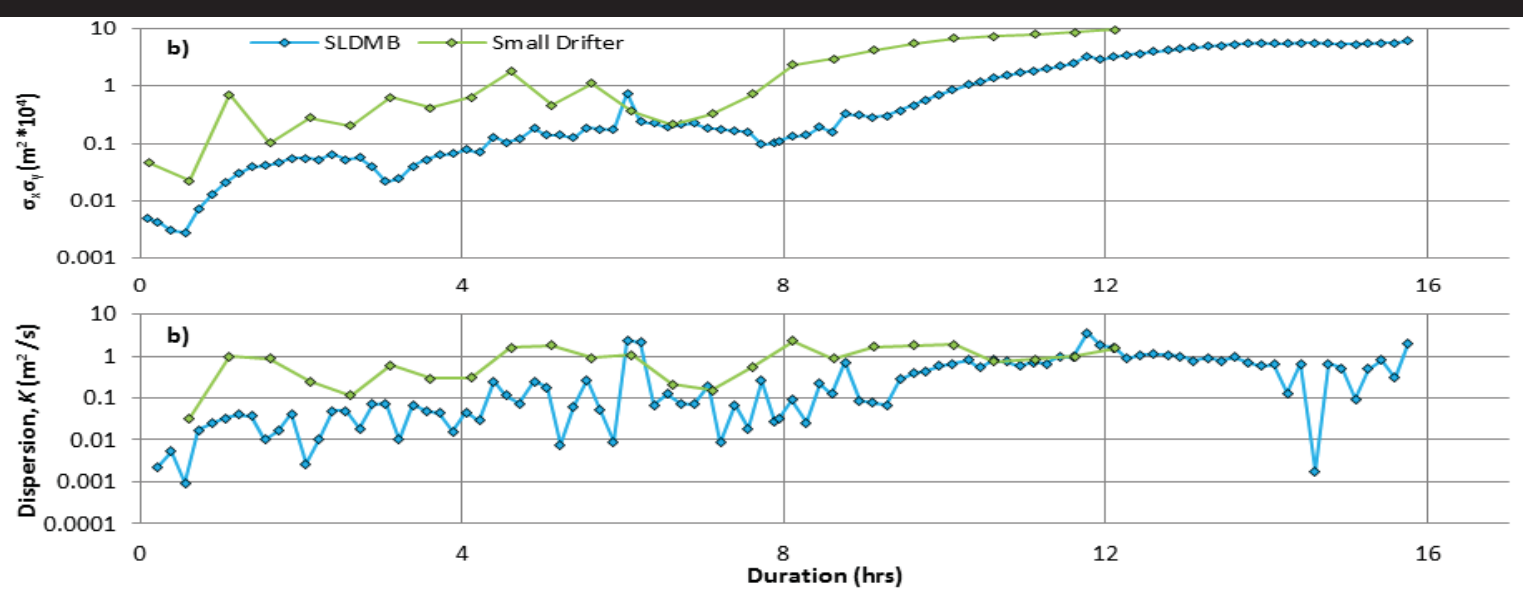

Figure 6. Dispersion behaviour comparison between SLDMBs and Small Drifters.

These analogies show that the Small Drifters were subject to greater dispersion than the SLDMBs the entire time. Both wind speed and direction were fluctuating during this trip, possibly causing chaotic Langmuir circulation ( $\mathrm{Li}, 2000)$, which appears to be the cause for the larger amount of dispersion for the Small Drifters. Given their similar displacement variance trend, both drifters seem to be tidally dominated.

\section{MIKE 3 vs. Drifters}

The model results were compared by superimposing the dispersion results onto the map that illustrated the dispersion of the drifters at each location (Figure 7). The output results from the model produced point data for four particles (in this case hypothetical drifters) which were simulated for the duration the

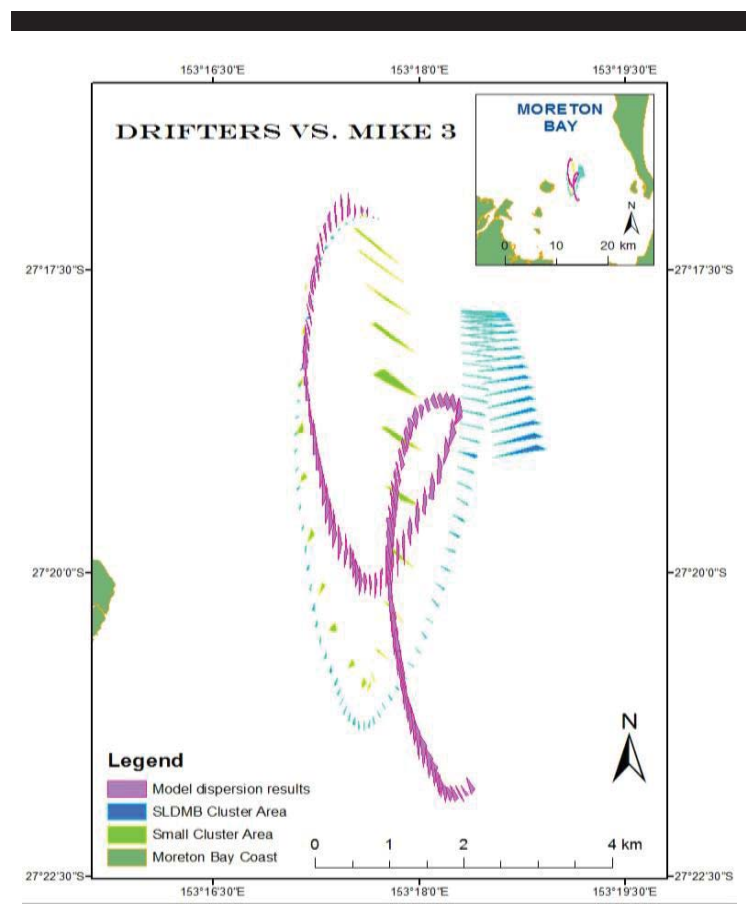

Figure 7. MIKE 3 dispersion and trajectory route compared to SLDMBs and Small Drifters drifters were in the water. Convex hulls were also used to represent the dispersion behaviour for the model results. The dispersion was overestimated for the first location during the first flood tide and, due to the steady nature of the dispersion simulated by the model, the dispersion did not increase during the ebb tide (as seen by the drifters). The difference in dispersion behaviour between the drifters and the model suggests that the dispersion coefficient of $0.2 \mathrm{~m}^{2} / \mathrm{s}$ was insufficient. The model did not satisfy the amount of dispersion exhibited by both drifters, and therefore the dispersion coefficient value should be increased. The trajectory route simulation appears to be a flaw with the model, which may be caused by using tide information provided by the DHI global tide model.

Figure 8 reinforces the assumption that MIKE 3 better correlates with disperison behaviour exhibited by the SLDMBs. Leading up to the $9^{\text {th }}$ hour, both MIKE 3 and the SLDMBs experience $K$ values around $0.1 \mathrm{~m}^{2} / \mathrm{s}$; whereas the Small Drifters experience values closer to $1 \mathrm{~m}^{2} / \mathrm{s}$. The mean and maximum dispersion values (Table 2) are larger than $0.1 \mathrm{~m}^{2} / \mathrm{s}$ for the SLDMBs due to the increase after the $9^{\text {th }}$ hour, reaching an average around $1 \mathrm{~m}^{2} / \mathrm{s}$.

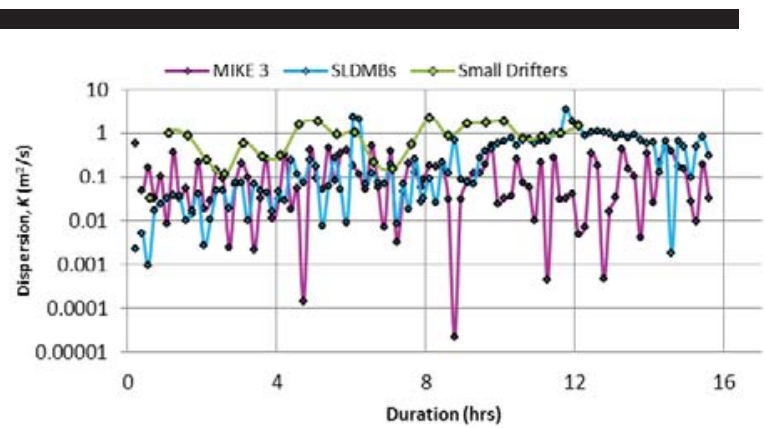

Figure 8. Dispersion showing a closer correlation with the SLDMBs

Table 2. Mean and maximum dispersion coefficient for MIKE 3, SLDMBs, and Small Drifters

\begin{tabular}{|l|l|l|}
\multicolumn{1}{c}{ Test } & \multicolumn{1}{c}{$\boldsymbol{K}$ mean } & \multicolumn{1}{c}{$\boldsymbol{K} \max$} \\
\hline MIKE 3 & 0.137 & 0.596 \\
\hline SLDMBS & 0.414 & 3.54 \\
\hline Small Drifters & 0.924 & 2.26 \\
\hline
\end{tabular}




\section{CONCLUDING REMARKS}

Two types of drifters were designed using a similar approached employed by Poulain (1999). In retrospect, it would have been ideal for the drifter designs to have been much more similar with respect to both the weight ratio and materials used. It would have been beneficial for the Small Drifters to have been made using the same cloth material for the vanes. Overall, the SLDMBs and Small Drifters clearly exhibited different dispersion behaviour. Results from this work highlights that drifters should be designed using well documented design regimes and any results need to be treated with great care. Further investigations should be performed to establish consistency with the dispersion and trajectory behaviour, including the impact of windage.

Adjustments to be made to MIKE 3 should certainly begin with developing a finer resolution spatial domain around the deployment locations. The model may benefit from using tidal predictions that are more accurate, which could potentially resolve issues associated with poor trajectory simulations.

\section{ACKNOWLEDGEMENT}

David Spencer would like to thank the Griffith School of Engineering for funding the project and the staff for great support. The research presented in this paper was conducted through the Griffith School of Environment Honours Program which also assisted with funding and support.

\section{LITERATURE CITED}

Breivik, Ø. and Allen, A.A., 2008. An operational search and rescue model for the Norwegian Sea and the North Sea. Journal of Marine Systems, 69(1-2), 99-113.

Charria, G., Lazure, P., Le Cann, B., Serpette, A., Reverdin, G., Louazel, S., Batifoulier, F., Dumas, F., Pichon, A. and Morel, Y., 2013. Surface layer circulation derived from Lagrangian drifters in the Bay of Biscay. Journal of Marine Systems, 109-110, S60S76.

Chilvers, B.L., Lawler, I.R., Macknight, F., Marsh, H., Noad, M. and Paterson, R., 2005. Moreton Bay, Queensland, Australia: an example of the co-existence of significant marine mammal populations and largescale coastal development. Biological Conservation, 122, 559-571.

DHI Water \& Environment., 2001. MIKE 3 Estuarine and Coastal Hydraulics and Oceanography. MIKE 3 Short Description Manual

Huhn, F., von Kameke, A., Allen-Perkins, S., Montero, P., Venancio, A. and Pérez-Muñuzuri, V., 2012. Horizontal Lagrangian transport in a tidal-driven estuary - Transport barriers attached to prominent coastal boundaries. Continental Shelf Research, 39-40, 1-13.

Jönsson, B.F., Döös, K., Myrberg, K. and Lundberg, P.A., 2011. A Lagrangian-trajectory study of a gradually mixed estuary. Continental Shelf Research, 31, 1811-1817.

Lewis, K. and J.I. Allen., 2009. Validation of a hydrodynamic-ecosystem model simulation with time-series data collected in the western English Channel. Journal of Marine Systems, 77, 296-311.

Li, M., 2000. Estimating Horizontal Dispersion of Floating Particles in Wind-driven Upper Ocean. Spill Science \& Technology Bulletin, 6, 255261.

Manley, T.O., 2010. Hands-on oceanography: Drifters, drogues, and circulation. Oceanography, 23, 165-171.

Marín, V.H. and Delgado, L.E., 2007. Lagrangian observations of surface coastal flows North of in the Humboldt Current system. Continental Shelf Research, 27, 731-743.

Narayan, Y.R. and Pandolfi, J.M., 2010. Benthic foraminiferal assemblages from Moreton Bay, South-East Queensland, Australia: Applications in monitoring water and substrate quality in subtropical estuarine environments. Marine Pollution Bulletin, 60, 2062-2078.

Poulain, P.M., 1999. Drifter observations of surface circulation in the Adriatic Sea between December 1994 and March 1996. Journal of Marine Systems, 20, 231-253.
Sabet, B.S. and Barani, G.A., 2011. Design of small GPS drifters for current measurements in the coastal zone. Ocean \& Coastal Management, 54, 158-163.

Tseng, R.S., 2002. On the Dispersion and Diffusion Near Estuaries and Around Islands. Estuarine, Coastal and Shelf Science, 54, 89-100.

Yu, Y., Zhang, H. and Lemckert, C., 2013a. Seasonal variations of the salinity and turbidity in the Brisbane River estuary, Queensland, Australia. Journal of Coastal Research, Special Issue No. 65, pp. 12531258, ISSN 0749-0208.

Yu, Y., Zhang, H. and Lemckert, C., 2013b. Numerical analysis on the Brisbane River plume in Moreton Bay due to Queensland floods 2010 2011. Environmental Fluid Mechanics, 1-24.

Zacharias, I. and Gianni, A., 2008. Hydrodynamic and dispersion modeling as a tool for restoration of coastal ecosystems. Application to a re-flooded lagoon. Environmental Modelling \& Software, 23, 751-767.

Zhang, H. and Chan, E., 2003. Modeling of the turbulence in the water column under breaking wind waves. Journal of oceanography, 59, 331341. 